\title{
Performance Evaluation of Bangalore Metropolitan Transport Corporation: An Application of Data Envelopment Analysis
}

\author{
Devaraj Hanumappa, Parthasarathy Ramachandran, T. G. Sitharam, \\ and S. Lakshmana \\ Indian Institute of Science, Bangalore
}

\begin{abstract}
Maintaining and enhancing public transit services in Indian cities is important to meet rapidly-growing mass mobility needs. Indian cities rely predominantly on buses for public transportation, and issues of performance measurement and efficiency analyses for bus companies have been gaining significance due to severe operational stress and financial constraints in which these bus companies provide service to people. In public transportation, multiple parameters are involved that influence the efficiency of operation. This study measures the performance of premium bus services operated by Bangalore Metropolitan Transport Corporation (BMTC) using data envelopment analysis. This approach enabled the identification of opportunities for improvement at the bus depot and route levels. The analysis indicates that most depots are efficient, but some routes have significant opportunities for improvement.
\end{abstract}

Keywords: Public transportation, Data Envelopment Analysis, efficiency analysis, transit

\section{Introduction}

From 1950-2010, the urban population in India grew from around 63 million to around 380 million and is expected to grow to around 600 million by 2030 (UN 2012). According to the 2011 census conducted by the Government of India, 53 Indian cities have 1+ million residents and 500 cities have $100,000+$ residents. These urban centers face significant challenges in moving people around because of inadequate infrastructure, increasing private vehicle ownership and resulting congestion, and inefficient public transportation systems. Public transportation is increasingly seen as the sustainable solution for urban mobility. Large investments are being made in public transportation projects in India. In 
this background, it is significantly important for public transportation to operate efficiently to derive returns from the large investments.

The use of standard cost and operational ratios for studying the performance of public transportation entities, although useful, does not provide a holistic view of operations. Data Envelopment Analysis (DEA) is being used under such circumstances with great success. In this paper, the performance of sub-units of Bangalore Metropolitan Transport Corporation (BMTC) using DEA was studied to identify opportunities for improvement. BMTC is a public transport organization operating in Bangalore, India. The population of Bangalore has been growing steadily; the city's population of 160,000 in 1901 has reached nearly 8.4 million in 2011 (CTTP 2007). BMTC came into existence in 1997 after bifurcation from its predecessor, Karnataka State Road Transport Corporation (KSRTC), with the sole aim of providing public transportation service in the urban and suburban areas of Bangalore City. The mission of the organization is to provide safe, reliable, clean, and affordable travel to every Bangalore resident. The salient features of BMTC are summarized in Table 1.

TABLE 1.

BMTC at a Glance

\begin{tabular}{|l|c|}
\hline Number of vehicles & 6,518 \\
\hline Number of schedules & 6,232 \\
\hline Daily schedule (million kms) & 1.3 \\
\hline Daily traffic revenue (rupees in million ) & 37.1 \\
\hline Number of trips & 76,593 \\
\hline Depots & 40 \\
\hline Staff employed & 36,464 \\
\hline Bus staff ratio (number of staff per bus) & 5.6 \\
\hline
\end{tabular}

Source: http://www.mybmtc.com/bmtc_glance

BMTC introduced different services to cater to segments of public transportation users of Bangalore. Although some consumers are very price-sensitive, others are willing to pay a premium for comforts such as air conditioning, low-floor convenience, and mobile/laptop charging facilities. Hence, BMTC introduced premium services using the latest chassis built by TATA Marcopolo and Volvo bus companies. These premium services began operation in February 2006 and provide service to different residential and information technology (IT) hubs in the city, and the separately-branded Vayu Vajra Premium services provide seamless connectivity between various parts of the city and the Bangalore International Airport. A total of 665 Volvo and Marcopolo air-conditioned buses are operated within the city and to the airport, constituting about $10 \%$ of the total number of buses in the BMTC stock, and operate from 4 four depots (see Figure 1), providing 3,700 trips and carrying 100,000+ passengers every day. 
FIGURE 1.

Depots for BMTC premium services

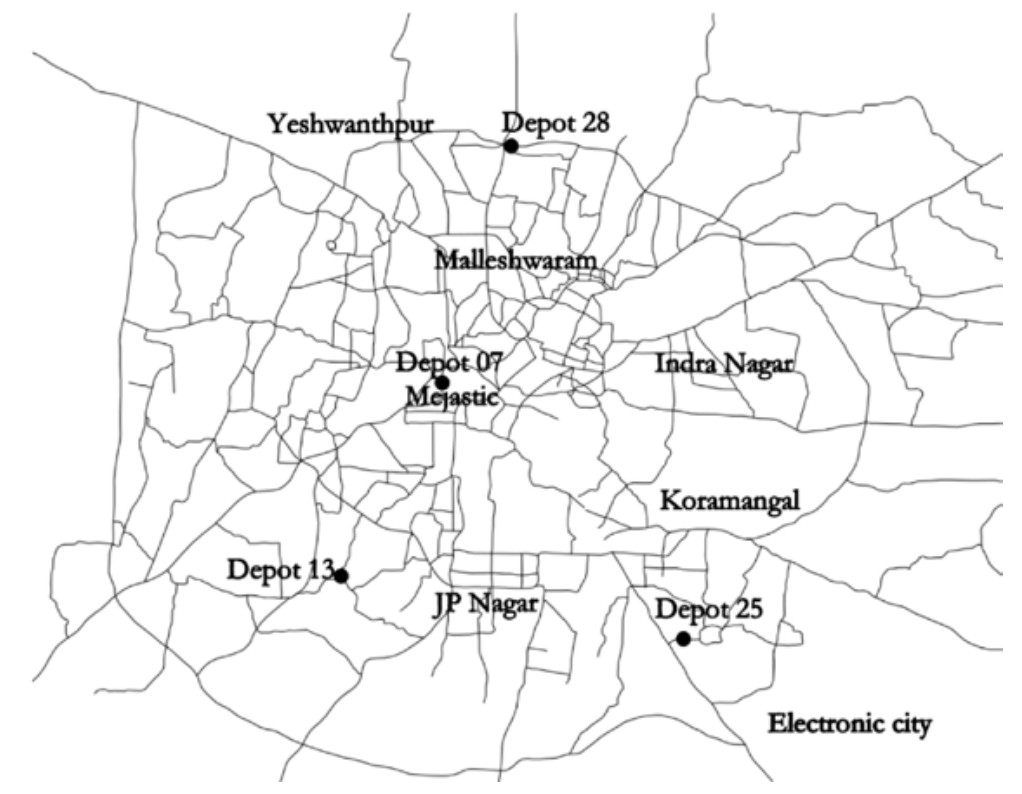

The main objective of this paper is to analyze the operations of the 4 premium service depots, 7 major premium service routes within the city, and 11 routes to the airport. The analysis is confined to premium services operated by Volvo buses only.

The existing literature points to ratio analysis and non-parametric techniques as the means to evaluate the performance of public transport systems. According to Nissam and Penman (2001), ratio analysis compares ratios for individual firms against comparable firms in the past and the present to get a sense of what is normal and what is abnormal. Alter (1976) used the perspective of the consumer to select six items for a composite index that included basic accessibility, travel time, reliability, directness of service, frequency of service, and passenger density for evaluation of mass transport service quality using levels of service. Feng and Wang (2001) used financial ratios for the performance evaluation of buses, with number of employees, number of maintenance employees, number of drivers, number of vehicles, fuel current assets, fixed assets, total assets, stock capital and stockholder equity as inputs and frequencies, vehicle-km, current liabilities, long-term liabilities, total liabilities, operation cost, and interest expense as product outputs. This approach typically considers one performance indicator at a time in evaluating an organization's performance and setting up benchmarks in a peer group.

The non-parametric approach provides the capability for a holistic perspective of an organization's performance. DEA is a very powerful non-parametric approach to study the relative performance of comparable organizations, referred to as decision making units (DMUs). Several studies have been carried out to analyze the efficiency of urban transport services using DEA (Levaggi 1994; Nolan 1996; Viton, 1998); Ramanathan 1999; Odeck 2000; Pina and Torres 2001; Karlaftis 2004; Agrawal et al. 2006; Odeck 2006; Sumar 2011). The major advantage of DEA is its capability to handle multiple inputs and outputs, implicit specification of the production function, and the ability to identify the source of inefficiency. The DEA method was adopted in this study aimed at evaluating the performance of BMTC. 


\section{Methodology}

A complex system such as a metropolitan transportation company has many dimensions to its operations, including financial performance, network connectivity, bus stock efficiency, etc. The DEA method assists in studying these different dimensions in a holistic fashion. DEA is a non-parametric method of efficiency measurement that provides a means of calculating apparent efficiency levels within a group of DMUs. The efficiency of a DMU is calculated relative to the group's observed best practice.

The DEA model consists of solving a mathematical optimization problem for each of the DMUs with the objective of maximizing the efficiency level of the unit being studied. Thus, if we consider $n$ homogeneous units $(j=1,2, \ldots n)$ with each of the units using the same set of $m$ inputs $\left(x_{1}, x_{2}, \ldots x_{m}\right)$ to obtain the same set of $s$ output $\left(y_{1}, y_{2}, \ldots y_{s}\right)$, the efficiency of DMU $o$ is calculated by solving the following linear programming problem (Charnes et al. 1978):

$$
\begin{aligned}
& L P_{0}=\operatorname{Max} \theta=\sum_{r=1}^{s} \mu_{r} y_{r o} \\
& \text { Subjected to } \sum_{r=1}^{s} \mu_{r} y_{r j} \leq \sum_{i=1}^{m} v_{i} x_{i j} \\
& \sum_{i=1}^{m} v_{i} x_{i o}=1 \\
& \mu_{1}, \mu_{2} \cdots \mu_{s} \geq 0 ; \quad v_{1}, v_{2} \cdots v_{m} \geq 0
\end{aligned}
$$

The efficiency of the DMU is calculated by maximizing the objective function (weighted sum of outputs), subjected to the constraints that weighted sum of inputs of DMU $o$ is standardized to 1 , and the efficiency of all the DMUs should be less than or equal to 1 . In the above model ( $L P o)$, the output weights are $\mu_{1}, \mu_{2}, \ldots \mu_{\mathrm{s}}$, and input weights are $v_{1}, v_{2}, \ldots v_{\mathrm{m}}$. The above model $(L P O)$ in primal form does not give any information about the inefficient DMU. Hence, the following dual variant of the model with the slack and surplus variables in the constraints is typically used:

$$
\begin{aligned}
& \left(D L P_{0}\right) \operatorname{Min} h_{0}=\theta_{0}-\sum_{i=1}^{m} S_{i}^{-}+\sum_{r=1}^{s} S_{r}^{+} \\
& \text {Subjected to } S_{i}^{-}=\theta_{0} x_{i 0}-\sum_{j=1}^{n} \lambda_{j} x_{i j} \quad, i=1,2, \ldots m \\
& S_{r}^{+}=\sum_{j=1}^{n} \lambda_{j} y_{r j}-y_{r 0}, \quad r=1,2, \ldots s \\
& S_{r}^{+}, S_{i}^{i}, \lambda_{j} \geq 0, \quad j=1,2, \ldots n
\end{aligned}
$$


In the optimal solution of model $\left(D L P_{0}\right)$

1. If $h_{0}=1$ and $S_{r}^{+}=S_{i}^{i}=0$, the DMU is called DEA efficient.

2. If $h_{0}<1$ and $S_{r}^{+} \neq 0, S_{i}^{i} \neq 0$, the DMUiscalled DEAinefficient.

Where,

$S_{r}^{+}=$represents the vector of non-negative slack associated with the output inequalities

$S_{i}=$ represents the vector of non-negative slack associated with the input inequalities

\section{Analysis and Discussion}

\section{Data}

The study was based on data provided by the Volvo Division Statistical Department of BMTC. The performance of the 4 depots that operate premium services, 7 premium services routes in the city, and 11 premium service routes to the airport were analyzed. The following depots that operate premium services were analyzed to evaluate their performance with the objective of identifying ways to improve their operations:

- Subashnagar (Depot-07)

- Katriguppa (Depot-13)

- HSR Layout (Depot-25)

- Hebbal (Depot-28)

BMTC classifies the premium service routes operated by these depots into three schedules:

- A-Schedules - revenues cover both variable cost and fixed cost of operation

- B-Schedules - revenues cover only the variable cost of operation

- C-Schedules - revenues are loss-making schedules whose revenues do not cover the variable cost of operation

This classification of the routes from the FY 2008/09 to FY 2011/2 is shown in Figure 2. The loss-making schedules (C-Schedules) decreased from 69\% in 2008/09 to $7 \%$ in 2011/12. The profit-making schedules (A-Schedules) increased from $10 \%$ to $75 \%$ in those same years, primarily because of route rationalization. Premium bus services began in 2006 with very few buses. As demand increased, new buses were procured, and the fleet size increased from 162 in 2009/10 to 464 in 2011/12, resulting in introduction of new routes with increased frequencies. Simultaneously, the ridership for these services also increased. In addition, Bangalore, being an IT hub, has a large demand for employee transportation, which was being serviced by cabs. Introduction of premium service buses caused a switch from cabs to buses. Factors such as these increased the revenue from these premium services from 26.6 rupees per kilometer in 2009/09 to 46.6 rupees per kilometer in 2011/12. 
FIGURE 2.

Variations in premium schedules 2008-2012

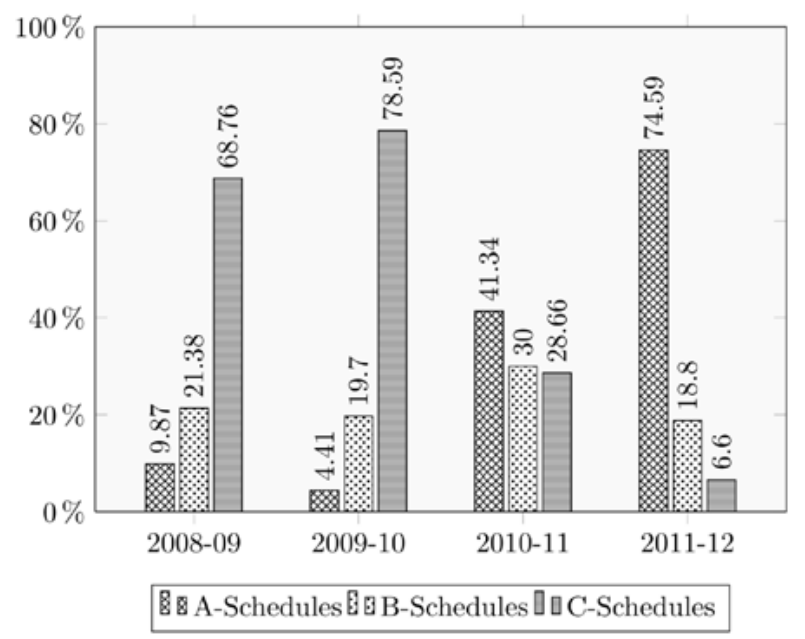

Some of the commonly-used input and output variables in the DEA analysis of urban transit systems identified from the literature review are summarized in Table 2.This includes some variables recommended by the Central Institute of Road Transport (CIRT) of India for monitoring the performance of transport corporations (CIRT 2009). CIRT studies the principles and practices of organizations and management in various spheres of public transportation in India, conducts research on critical issues in transport development, and provides training and education to managers and professionals engaged in public transport. It also helps the government and its agencies in evolving integrated policies and legislative frameworks to enable a balanced growth of the transport sector. Based on the list of variables from the literature and data availability from BMTC, the following variables were used for analysis.

TABLE 2.

Commonly-Used Input and Output Measures in DEA of Urban Transit Systems

\begin{tabular}{|l|l|}
\hline \multicolumn{1}{|c|}{ Input Measures } & \multicolumn{1}{c|}{ Output Measures } \\
\hline Number of employees & Distance traveled \\
\hline Fuel consumption & Vehicle kilometers \\
\hline Fleet size & Passenger count \\
\hline Average speed & Passenger kilometers \\
\hline Fleet average age & Fleet size per unit distance per employee \\
\hline Cost per unit distance & Accident rate \\
\hline Driving hours & Revenue per passenger per unit distance \\
\hline Effective kilometers traveled & Revenue per day \\
\hline Number of schedules & Revenue \\
\hline & Fleet utilization \\
\hline & Breakdown rate \\
\hline & Fuel efficiency (kilometers per liter) \\
\hline & Staff productivity \\
\hline & Profitability \\
\hline & Vehicle utilization \\
\hline
\end{tabular}


Input variables included:

- Fleet size as a measure of capital input

- Number of employees as a measure of labor input

- Fuel consumed as a measure of energy input

- Number of schedules and effective kilometres as a measure of network size

Output variables included:

- Total revenue generated and profitability - the ratio of EPKM (earnings per kilometer) and cost per kilometer (CPKM) as a measure of financial performance

- Vehicle utilization, fleet utilization, staff productivity, breakdown rate, and fuel efficiency (in terms of kilometer per liter) as measures of operational effectiveness

- Accident rate as a measure of operational safety

\section{Short Run and Long Run Effect}

A metropolitan bus transport company has both fixed and variable inputs. Fixed inputs are those that cannot be changed on short notice, such as a change in the fleet size, which will involve a fixed set of administrative procedures either to procure a new vehicle or scrap an existing vehicle and, hence, typically would involve a significant amount of time. A variable such as the number of schedules is an operational decision that can be modified relatively easily. Hence, the variables were divided, and the performance of BMTC was analyzed as long-run and short-run performance based on the variables considered.

\section{Long Run Performance Analysis}

Fleet size and number of employees typically are fixed in the short run and are long-run input variables. Fuel consumed, number of schedules, and total effective kilometers traveled are inputs that can be modified regularly and are short-run input variables. The output variables that are strongly influenced by these input variables are long-run output variables. Although some long-run variables might be influenced by short-run variables and decisions, it was assumed that these short-term variables/decisions are taken optimally by the organization in performing this long-run analysis. For example, the total revenue generated by the transport company is a function of the vehicles it operates, so it is a long-run output measure. Revenue generation also is influenced by fleet scheduling, a short-run input variable. Since fleet schedules are derived for a specific fleet, we assume that the short-run fleet schedules are optimally taken while performing the long-run analysis. Further, fleet utilization, defined as the ratio of total number of vehicles on road to the total number of vehicles held by the company, is influenced by the long-run input variable of fleet size and is considered to be a long-run output measure. Similarly, the staff productivity measure, defined as the ratio of the total number of kilometers operated by all the vehicles assigned to the depot to the total number of staff assigned to the depot, is defined in terms of both long-run input measures and is taken to be a long-run output measure. 
The DEA long-run analysis was performed on monthly data for FY 2011/12 using the above long-run input and output variables. The technical efficiency results are shown in Table 3.

TABLE 3.

Efficiency Scores of BMTC Premium Service Depots Using Long-Run Variables

\begin{tabular}{|l|c|c|c|c|c|}
\hline \multirow{2}{*}{ Month } & \multirow{2}{*}{ Depot-07 } & \multicolumn{2}{|c|}{ Depot-13 (Dual Programming) } & \multirow{2}{*}{ Depot-25 } & \multirow{2}{*}{ Depot-28 } \\
\cline { 4 - 5 } & & & Peer Group & \\
\hline April 2011 & 1.000 & 0.926 & $07,25,28$ & 1.000 & 1.000 \\
\hline May 2011 & 1.000 & 0.868 & $07,25,28$ & 1.000 & 1.000 \\
\hline June 2011 & 1.000 & 0.891 & 25,28 & 1.000 & 1.000 \\
\hline July 2011 & 1.000 & 0.882 & 25,28 & 1.000 & 1.000 \\
\hline August 2011 & 1.000 & 0.893 & $07,25,28$ & 1.000 & 1.000 \\
\hline September 2011 & 1.000 & 0.856 & $07,25,28$ & 1.000 & 1.000 \\
\hline October 2011 & 1.000 & 0.892 & $07,25,28$ & 1.000 & 1.000 \\
\hline November 2011 & 1.000 & 0.906 & $07,25,28$ & 1.000 & 1.000 \\
\hline December 2011 & 1.000 & 0.978 & 25,28 & 1.000 & 1.000 \\
\hline January 2012 & 1.000 & 0.934 & 07,28 & 1.000 & 1.000 \\
\hline February 2012 & 1.000 & 0.978 & 07,28 & 1.000 & 1.000 \\
\hline March 2012 & 1.000 & 1.000 & $\mathrm{~N} / \mathrm{A}$ & 1.000 & 1.000 \\
\hline
\end{tabular}

It can be observed from the results that the efficiency scores from the long-run DEA model for Depots 07, 25, and 28 are 100\%, and Depot 13 has an average efficiency of about $91.7 \%$. The results show that the Depots 07,25 , and 28 are consistent performers throughout the year. The average performance of all the depots is above $97 \%$ throughout the year. Depot 13 is the inefficient depot; hence, the input and output slack values were calculated using the dual linear programming (DLPo) model. The peer group for the inefficient DMU is also noted in Table 3. The potential for reduction in input or increase in output for Depot 13, expressed as the percentage decrease or increase from current levels, is shown in Figure 3, which shows that Depot 13 has significant potential for increases in staff productivity, fleet utilization, and reduction in number of employees.

FIGURE 3.

Slack and surplus values for Depot 13

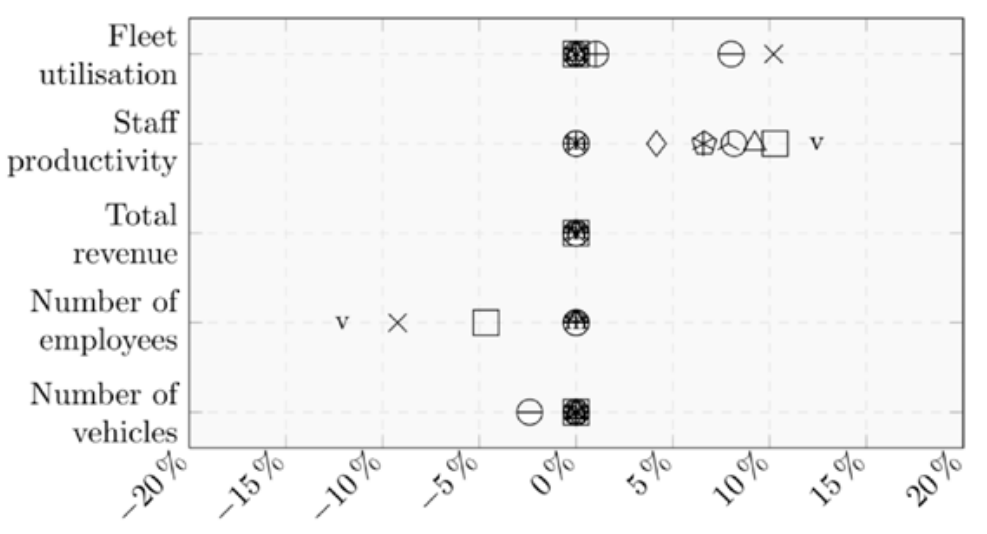

$\triangle$ Apr $11 \triangle$ May $11 \square$ Jun $11 \bigcirc$ Jul $11 *$ Aug $11 \diamond$ Sep 11 $\oplus$ Oct 11 人 Nov $11 \ominus$ Dec $11 \times$ Jan 12 v Feb 12 m Mar 12 
As shown in Figure 1, Depot 07 is located in the central part of the city and is the major hub through which people transfer. Depot 25 is located in a prime residential area located close to one of the major IT hubs in Bangalore. Depot 28 is in a densely-populated area along the route to the airport and is the fastest-growing area in Bangalore. These factors could contribute to the superior performance of these depots. However, Depot 13 shows potential for improvement by reducing the number of employees or increasing staff productivity and fleet utilization. This depot is located in an area far from the IT companies and commercial settlements and mainly operates short routes, which could be a factor contributing to its lower fleet utilization and staff productivity.

\section{Short Run Performance Analysis}

The performance of BMTC using the short-run variables was studied. The number of schedules, effective kilometers (kilometers run in a day, net of dead kilometers), and fuel consumption are the short-run input variables. The output variables affected by these inputs-namely, breakdown rate (number of vehicle breakdowns per 10,000 vehicle kilometers), accident rate (number of vehicle accidents per 100,000 vehicle kilometers), fuel efficiency (kilometers traveled per liter of fuel consumed), vehicle utilization (average daily kilometers operated per vehicle per day), and profitability (ratio of earnings per kilometer to cost per kilometer)-are the short-run output measures. The results from the DEA analysis using the short-run variables on the monthly data for the FY 2011/12 are shown in Table 4. The potential improvement for the inefficient DMUs, expressed in terms of percentage decrease or increase from the current levels, is shown in Figure 4, which shows that there is potential for improvement in breakdown rate, fuel efficiency, profitability, vehicle utilization, and effective kilometers.

TABLE 4.

Efficiency Scores of BMTC Premium Service Depots Using Short-Run Variables

\begin{tabular}{|l|c|c|c|c|}
\hline \multicolumn{1}{|c|}{ Month } & Depot-07 & Depot- 13 & Depot-25 & Depot-28 \\
\hline April 2011 & 0.706 & 0.704 & 1.000 & 1.000 \\
\hline May 2011 & 0.749 & 0.696 & 1.000 & 1.000 \\
\hline June 2011 & 0.738 & 0.699 & 1.000 & 1.000 \\
\hline July 2011 & 0.787 & 0.739 & 0.898 & 1.000 \\
\hline August 2011 & 0.572 & 0.676 & 0.907 & 1.000 \\
\hline September 2011 & 0.716 & 1.000 & 0.915 & 1.000 \\
\hline October 2011 & 0.593 & 0.858 & 0.906 & 1.000 \\
\hline November 2011 & 0.717 & 1.000 & 0.999 & 1.000 \\
\hline December 2011 & 0.712 & 1.000 & 0.897 & 1.000 \\
\hline January 2012 & 0.710 & 1.000 & 1.000 & 1.000 \\
\hline February 2012 & 0.650 & 1.000 & 1.000 & 1.000 \\
\hline March 2012 & 1.000 & 1.000 & 1.000 & 1.000 \\
\hline
\end{tabular}


FIGURE 4.

Slack and surplus values for inefficient depots using short-

term variables

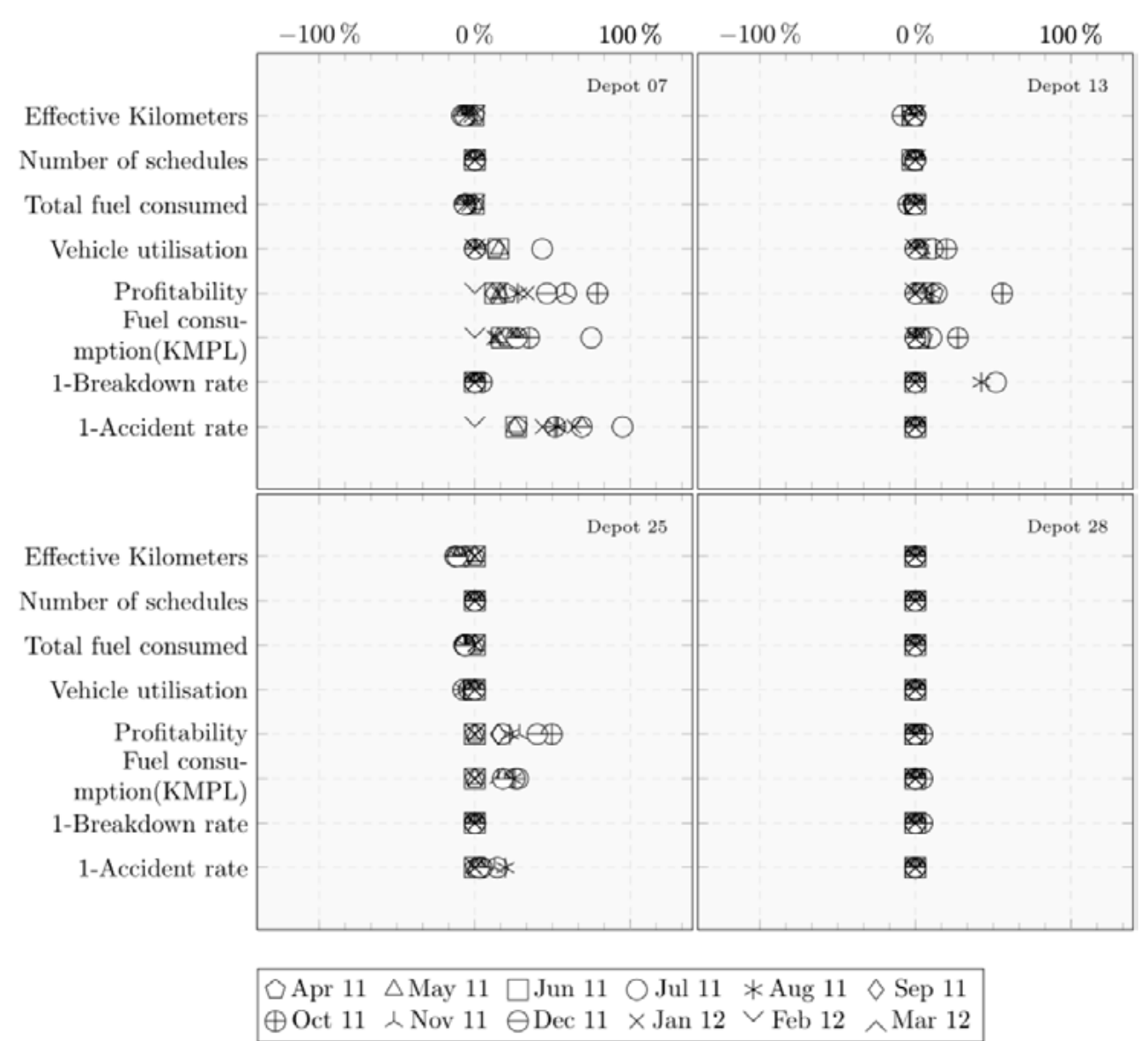

The results show that the average efficiency of the Depots $07,13,25$, and 28 are 0.721 , $0.864,0.960$ and 1.000 , respectively. There is potential for increased profitability, kilometers per liter, vehicle utilization, and breakdown rate. Depots 07,13 , and 25 are located in heavily-congested areas, resulting in much vehicle idling and waiting time. This could explain poor kilometers per liter and utilization of vehicles in these depots. Further, the increased breakdown rates in Depot 07 could be a vestige of historical vehicle assignments to the depots; the initial lot of vehicles was assigned to operate out of Depot 07 , and the typical age of buses in Depot 07 is much higher than those in the other depots.

\section{Sample Size Issues}

The efficiency scores computed for each DMU using DEA are sensitive to sampling variations, particularly when small samples are used. It has been reported that DEA analysis typically has an upward bias in efficiency due to dimensionality issues when the sample size is limited compared to the number of inputs and output variables (see Perelman and Santin 2009; Simar 2007; Coelli et al. 2005; Staat 2001; Smith 1997; Banker 1993).

The DEA bootstrap, or smoothed bootstrap, is a combination of the original bootstrap method (Efron 1979) modified with a smoothing parameter (Silverman 1986) and DEA (Charnes et al. 1978) designed to overcome the upward bias in efficiency estimation. Simar and Wilson (1998) managed to estimate bias in the DEA efficiency scores that is due to sampling variations by applying a smoothed bootstrap for generating random- 
ly-sampled efficiency scores that were then used for estimating bootstrapped inputs (input-oriented approach) or outputs (output-oriented approach). Subsequently, the bootstrapped inputs or outputs were introduced to the DEA linear programming models for bias-corrected efficiency scores.

There is a strong suspicion of this upward bias since the number of DMUs in this study is only four. Hence, we sought to estimate the quantity of this upward bias by applying the bootstrap technique. Specifically, we adopted the SW algorithm proposed by Simar and Wilson (1998), in which the bootstrap frontier and the bootstrap efficiency estimates were re-sampled based on a re-sampling of technical efficiencies from the empirical distribution of the original estimates of efficiency. Furthermore, the bootstrap, a replicate of efficiency, is based on the re-sampled data in the same manner as the original estimates were based on the original data.

The efficiency results from the original model and the bootstrapped approach are shown in Table 5. It is observed that the bootstrapping efficiencies are comparatively less that the original DEA efficiency. This confirms the presence of upward bias due to the small sample size. The average bootstrapping efficiencies of Depots $07,13,25$, and 28 are 0.587 , $0.759,0.853$, and 0.999 , respectively, compared to the original efficiencies of $0.725,0.865$, 0.960 , and 1.000 .

TABLE 5.

Results of Bootstrapping DEA for BMTC Premium Service Depots Using Short-Run Variables

\begin{tabular}{|l|c|c|c|c|c|c|c|c|}
\hline \multirow{2}{*}{ Month } & \multicolumn{2}{|c|}{ Depot-07 } & \multicolumn{2}{c|}{ Depot-13 } & \multicolumn{2}{c|}{ Depot-25 } & \multicolumn{2}{c|}{ Depot-28 } \\
\cline { 2 - 9 } & $B$ & $O$ & $B$ & $O$ & $B$ & $O$ & $B$ & $O$ \\
\hline April 2011 & 0.572 & 0.746 & 0.657 & 0.704 & 0.828 & 1.000 & 1.000 & 1.000 \\
\hline May 2011 & 0.571 & 0.749 & 0.668 & 0.696 & 0.855 & 1.000 & 1.000 & 1.000 \\
\hline June 2011 & 0.571 & 0.740 & 0.671 & 0.703 & 0.862 & 1.000 & 1.000 & 1.000 \\
\hline July 2011 & 0.568 & 0.791 & 0.666 & 0.740 & 0.857 & 0.902 & 0.993 & 1.000 \\
\hline August 2011 & 0.568 & 0.569 & 0.653 & 0.681 & 0.893 & 0.902 & 1.000 & 1.000 \\
\hline September 2011 & 0.586 & 0.717 & 0.833 & 1.000 & 0.856 & 0.918 & 1.000 & 1.000 \\
\hline October 2011 & 0.562 & 0.591 & 0.824 & 0.858 & 0.885 & 0.906 & 1.000 & 1.000 \\
\hline November 2011 & 0.569 & 0.717 & 0.858 & 1.000 & 0.826 & 0.995 & 1.000 & 1.000 \\
\hline December 2011 & 0.559 & 0.714 & 0.817 & 1.000 & 0.831 & 0.901 & 1.000 & 1.000 \\
\hline January 2012 & 0.567 & 0.711 & 0.814 & 1.000 & 0.844 & 1.000 & 1.000 & 1.000 \\
\hline February 2012 & 0.536 & 0.650 & 0.845 & 1.000 & 0.862 & 1.000 & 1.000 & 1.000 \\
\hline March 2012 & 0.809 & 1.000 & 0.801 & 1.000 & 0.834 & 1.000 & 0.991 & 1.000 \\
\hline Average & 0.587 & 0.725 & 0.759 & 0.865 & 0.853 & 0.960 & 0.999 & 1.000 \\
\hline
\end{tabular}

$B=$ bootstrap, $O=$ original

\section{Analysis of Premium Service Routes}

The performance of 7 city premium service routes and 11 premium service routes to the airport was studied. The data availability at the service route level was rather restricted. We considered the fleet size and total effective kilometers traveled by all buses as input variables and total revenue generated as the output variable. The analysis was confined to FY 2011/12 from April 2011 to March 2012. Figure 5 shows the premium service routes, and Figure 6 shows the premium service routes to the airport. 
FIGURE 5.

Premium service city routes

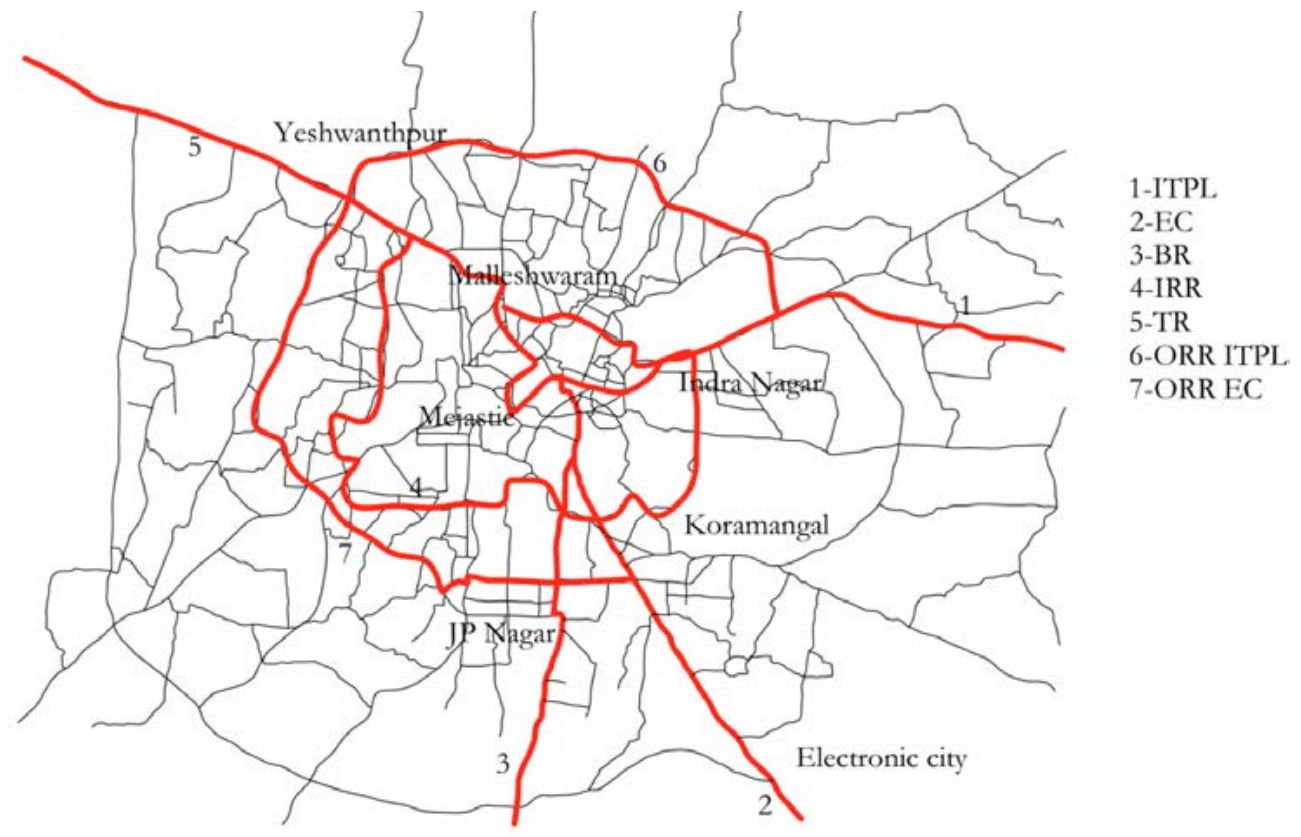

FIGURE 6.

Premium service airport routes

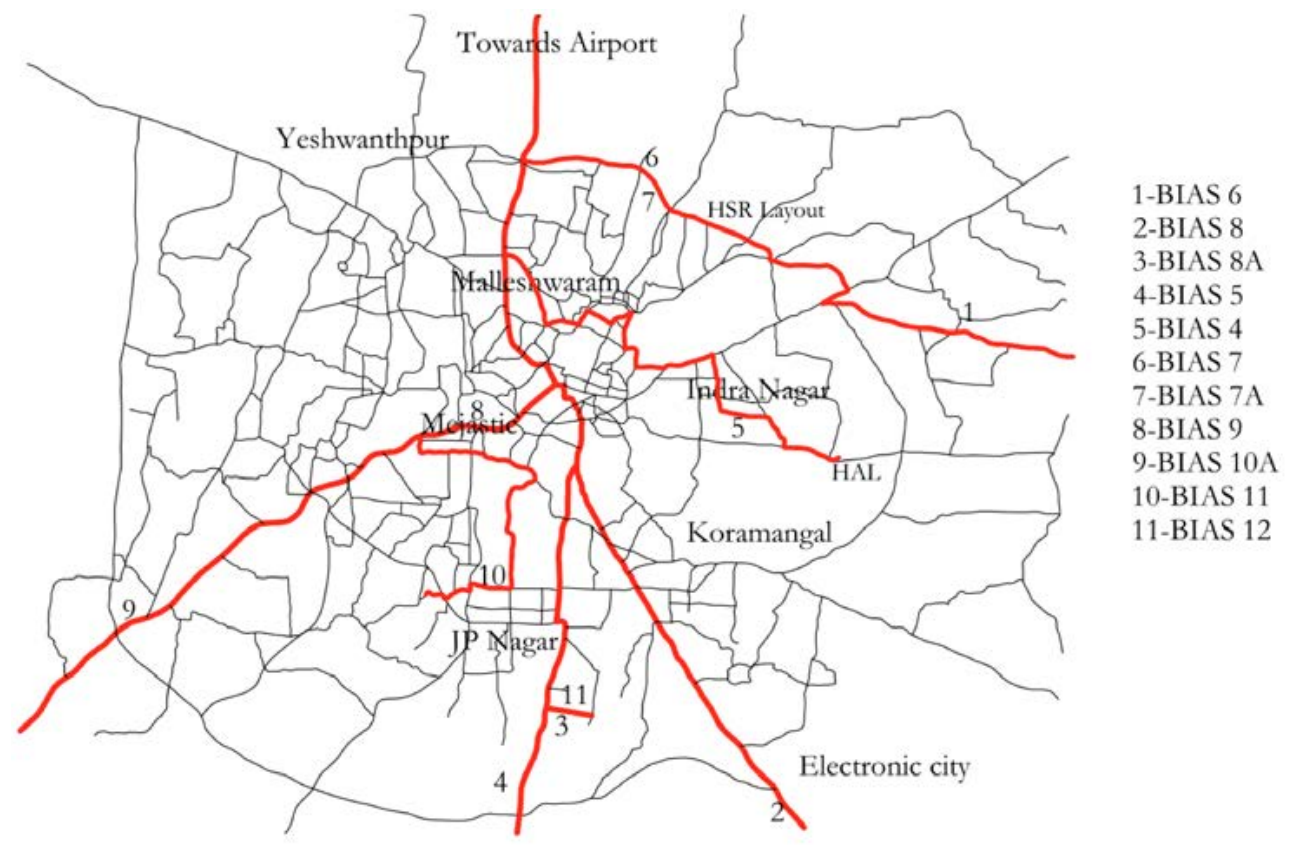

The results of the DEA analysis on these routes are shown Figures 7 and 8 . It can be observed from the results shown in Figure 7 that the premium service city routes clusters into two groups; (1) ITPL, EC, BR, IRR, and ORRITPL, which have very high technical efficiencies, in the range of about $95 \%$, and (2) TR and ORREC, which have relatively low technical efficiencies, in the mid- $80 \%$ range. This could be for the following reasons:

- The Tumkur road corridor is a major small scale industry corridor in Bangalore, and the surrounding residential areas are not economically affluent to demand premium service. 
- The areas surrounding the Outer Ring Road-EC are semi-urban in nature in comparison with the Outer Ring Road-ITPL corridor. This might be the reason for the underperformance of the Outer Ring Road-EC route.

FIGURE 7.

Efficiency score of 7 BMTC premium services operated in

city routes

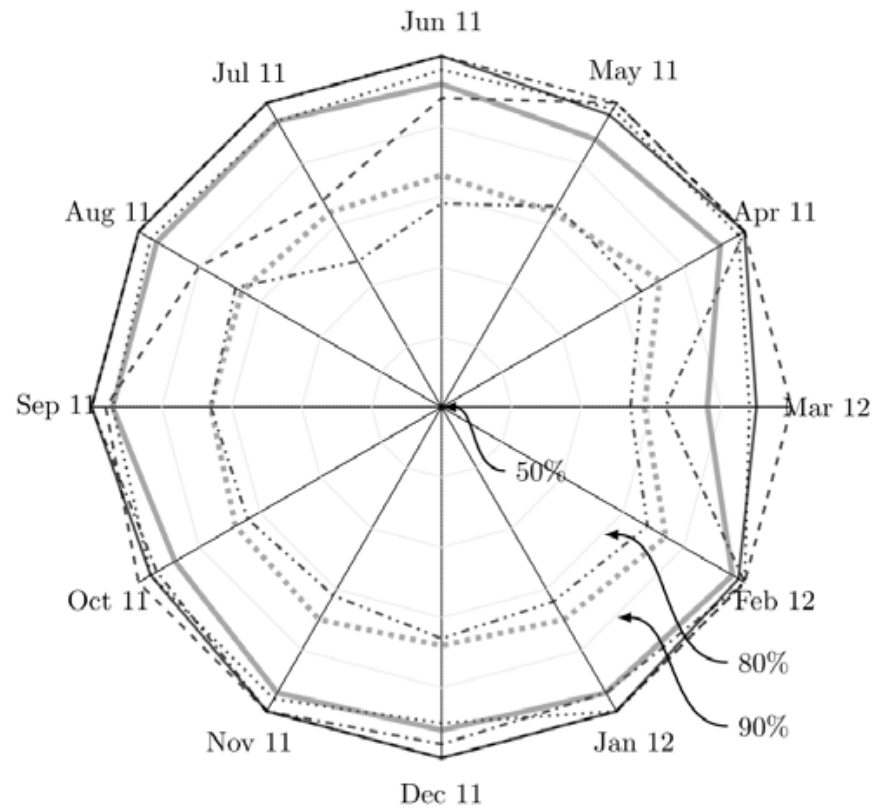

- ITPL $\cdots \cdots$ EC --- BR $\cdots \cdots$ IRR $\cdots \cdots$ TR — ORRITPL $\cdots \cdots$ ORREC

FIGURE 8.

Efficiency score of 11 BMTC premium services operated to airport

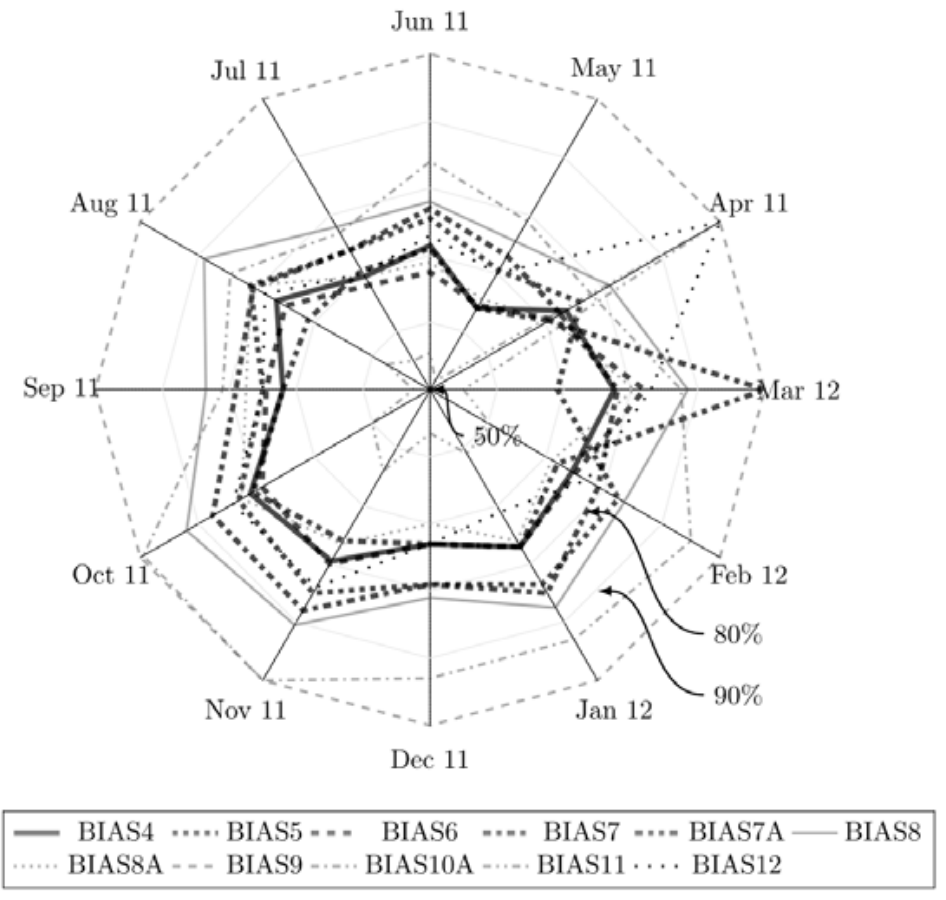


Efficient frontier for premium

city routes

The relative performance of these routes also can be viewed from the position of the DMUs in the output standardized input variable space (see Figure 9). The plot for April 2011 data shows that the DMUs ITPL, Bannerghatta Road, and Inner Ring Road form an efficient frontier, in line with the findings of the DEA model. The potential improvement in performance for these routes computed from the slack and surplus in the DEA model is expressed as percentage change from the current levels in Figure 10, which indicates that all the routes have potential for a decrease in fleet size or an increase in revenue. The Tumkur Road and Outer Ring Road-EC routes show opportunities for significant performance improvements by generating additional revenue or by reducing fleet size. The effective kilometers of operation do not seem to provide much potential for improvement.

FIGURE 9.

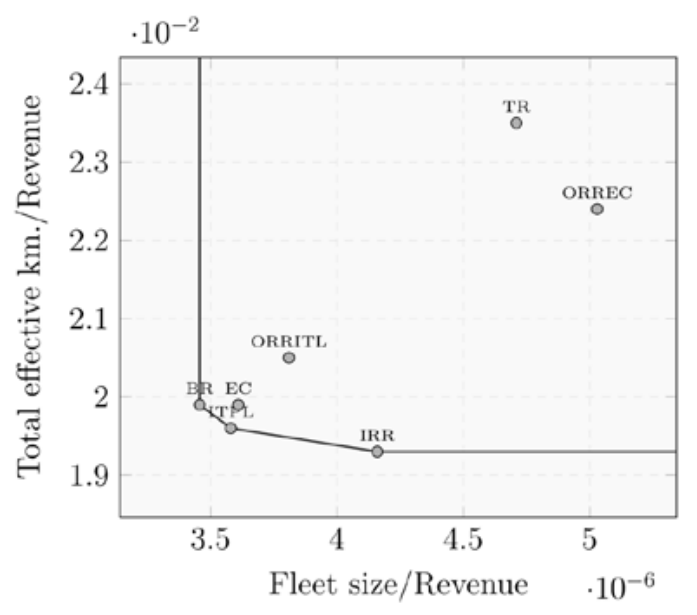

FIGURE 10.

Slack and surplus for inefficient city routes

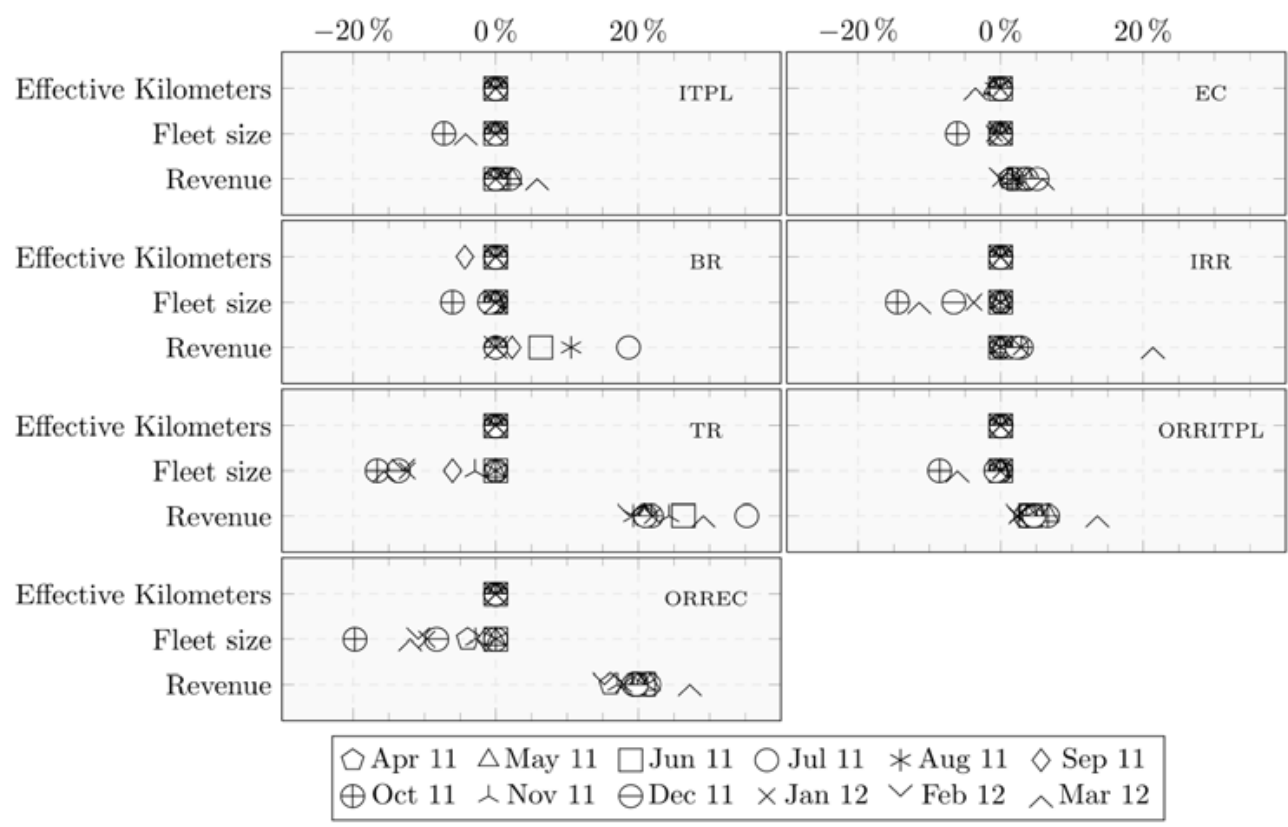


FIGURE 11.

Slack and surplus for inefficient airport service routes
Similar analysis on the premium service airport routes was conducted; the results are shown in Figure 11, which shows that the BIAS 9 route (Kempegowda bus stand to airport) is the only route with a $100 \%$ efficiency score; all other routes show relatively lower efficiency scores.

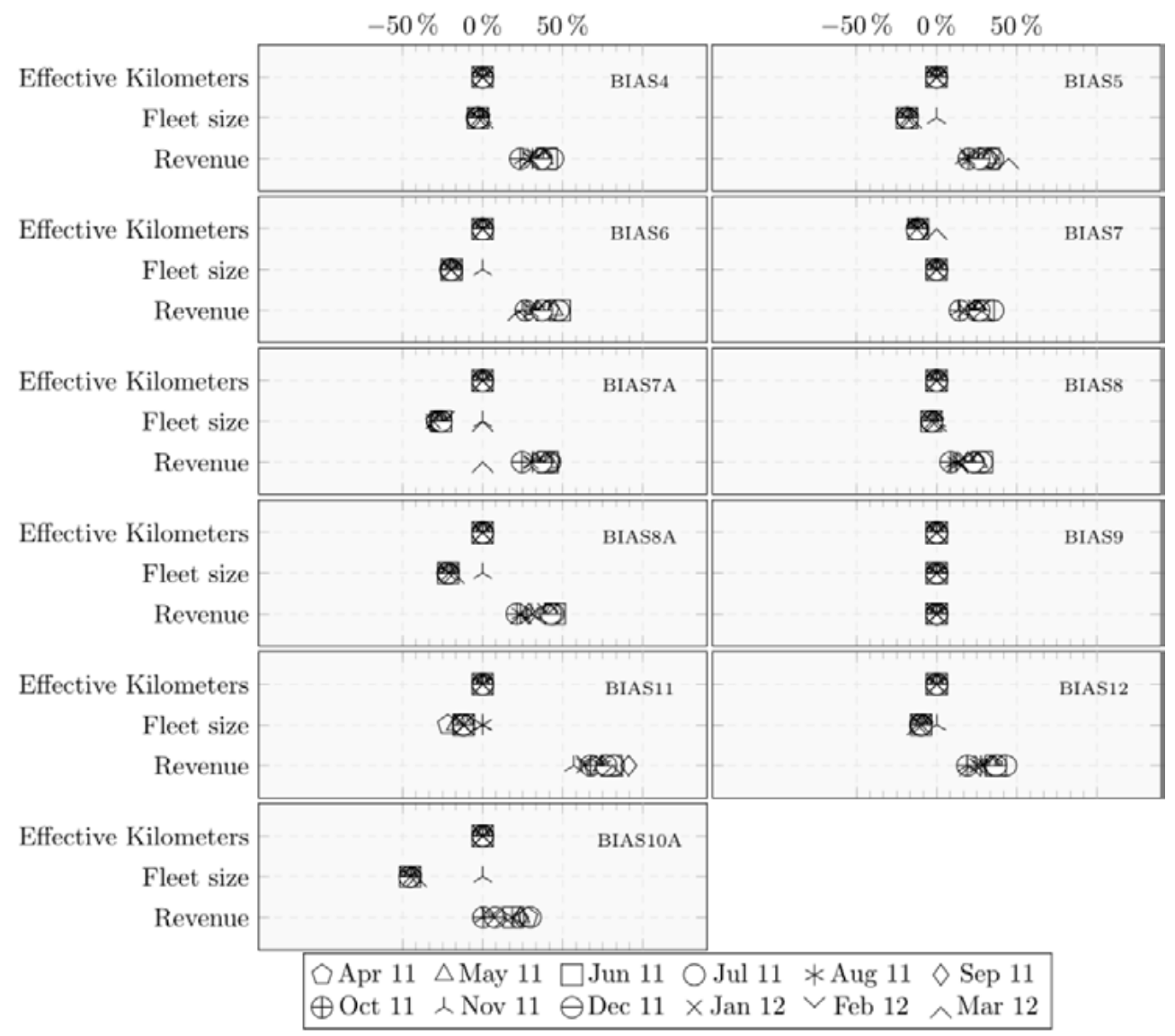

The main reason for this could be due to the fact that the Kempegowda bus stand is in the city center and is a major transfer hub. Further, BIAS11 (Chikkalasandra bus stand to airport) shows a much lower efficiency, in the 50-60\% range, than the other routes, which have efficiencies in the $70-90 \%$ range. The BIAS11 route starts from the same area in which Depot 13 is located, which was identified as an inefficient depot in the earlier analysis. A common set of socio-economic factors of the area could be contributing to the inefficiencies.

The other routes that have moderate technical efficiencies (70-90\%) operate from different suburbs of Bangalore to the airport, and only people traveling to the airport typically use these services. Also, these services operate around the clock, with lower load factors during the night-time schedules, and they operate with only half the number of seats. The other main reason for the lower efficiency could be related to fares, which are nearly equal to the cost of private transportation modes such as taxis and could be experiencing severe competition from them. 
Figure 11 shows the improvement potential for the inefficient BIAS routes expressed as percentage reduction in input or percentage increase in output from the current levels. All the inefficient BIAS routes show significant revenue increase potential compared with the levels achieved in BIAS9 with BIAS11, and as expected, lead the pack with maximum potential improvement. Also, some routes show potential for fleet size reduction.

\section{Conclusions}

The main objective of this study was to quantify the performance of premium bus services operated by BMTC. The efficiency scores for different premium service depots and routes using DEA were estimated, and it was found that the average long-term efficiencies of all premium service depot range between 1.00 (for Depots 07, 25, and 28) and 0.917 (Depot 13), with a systemwide average efficiency of 0.97 . Similarly, the short-term efficiencies vary-0.725 (Depot 07), 0.865 (Depot 13), 0.960 (Depot 25), and 1.00 (Depot 28). The bootstrapping process for short-term efficiency showed the presence of upward bias in efficiency estimates with low sample sizes. This analysis indicated that the inefficient units have opportunities for improvement in terms of staff productivity, indicating a need to align depot staffing patterns with needs.

The efficiencies of the premium services operated within the city ranged from 1.00 to 0.77 , with an average of 0.93 for the 7 service routes. The efficiency values of the 11 premium services operated to the airport ranged from 0.61 to 1.00 , with an average of 0.79 .

The main finding from this study is that, despite increases in the cost of operation in terms of fuel cost and maintenance cost, the BMTC premium service depots appear to be operating efficiently. At the same time, some of the city and airport routes show potential for improvement. The revenue generated by the various inefficient routes appears to be significantly inadequate, as indicated by the slacks, pointing at the need to rationalize the routes and schedules for a more efficient operation.

\section{Acknowledgments}

The authors thank the management of BMTC for their willingness to share the microscopic data of their depots and their diligence in maintaining a high-quality data set. Also, thanks to CiSTUP (CiST045) and HSMI/HUDCO (HSMI001; HUDCO/R/\&D/3/2012) for financial support through research projects awarded to the third author for carrying out this work.

\section{References}

Agrawal, S., S. P. Yadav, and S. P. Singh. 2006. "A Data Envelopment Based Efficiency Assessment of Public Transit Sector of Uttar Pradesh State in India." Indian Journal of Transport Management, 30 (1): 5-30.

Alter, C. H. 1976. "Evaluation of Public Transit Services: The Level-of-Service Concept." Transportation Research Record, 37-40. 
Banker, R. D. 1993. "Maximum-Likelihood, Consistency and Data Envelopment Analysis: A Statistical Foundation." Management Science, 39 (10): 1265-1273.

Button, K., and A. Costa. 1999. "Economic Efficiency Gains from Urban Public Transport Regulatory Reform: Two Case Studies of Changes in Europe." Annals of Regional Science, 33: 425-438.

Central Institute of Road Transport (CIRT). 2009. Compendium of Transport Terms, 7th Edition.

Chang, K.-P., and P.-H. Kao. 1992. "The Relative Efficiency of Public versus Private Municipal Bus Firms: An Application of Data Envelopment Analysis." Journal of Productivity Analysis, 3: 67-84.

Charnes, A., W. W. Cooper, and E. Rhodes. 1978. "Measuring the Efficiency of Decision Making Units." European Journal of Operational Research, 2 (6): 429-444.

Chen, C.-M., J. Du, J. Huo, and J. Zhu. 2012. “Undesirable Factors in Integer-Valued DEA: Evaluating the Operational Efficiencies of City Bus Systems Considering Safety Records." Decision Support Systems, 54: 330-335.

Coelli, T. J., D. S. Prasada Rao, C. J. O'Donnell, and G. E. Battese. 2005. An Introduction to Efficiency and Productivity Analysis, 2nd Edition. Springer, New York.

Cowie, J., and D. Asenava. 1999. "Organisation Form, Scale Effects and Efficiency in the British Bus Industry." Transportation, 26: 231-248.

Efron, B. 1979. "Bootstrap Methods: Another Look at the Jacknife." Annals of Statistics, 1: $1-26$.

Feng, C.-M., and R.-T. Wang. 2001. Considering the Financial Ratios on the Performance Evaluation of Highway Bus Industry." Transport Reviews, 21 (4): 449-467.

Garcia Sanchez, I. M. 2009. "Technical and Scale Efficiency in Spanish Urban Transport: Estimating with Data Envelopment Analysis." Advances in Operations Research.

Government of India Enterprise RITES, Ltd. 2007. "Comprehensive Traffic and Transportation Plan for Bangalore," October 2007.

Hahn, J.-S., D.-K. Kim, H.-C. Kim, and C. Lee. 2013. "Efficiency Analysis on Bus Companies in Seoul City Using a Network DEA Model." KSCE Journal of Civil Engineering, 17 (6): 1480-1488.

Han, J., and Y. Hayash. 2008. "A Data Envelopment Analysis for Evaluating the Performance of China's Urban Public Transport Systems." International Journal of Urban Sciences, 12 (2):173- 183.

Hawas, Y. E., M. B. Khan, and N. Basu. 2012. "Evaluating and Enhancing the Operational Performance of Public Bus Systems Using GIS-Based Data Envelopment Analysis." Journal of Public Transportation, 15 (2): 19-44.

Jain, P., S. Cullinane, and K. Cullinane. 2008. "The Impact of Governance Development Models on Urban Rail Efficiency." Transportation Research Part A, 42 (6): 1238-1250. 
Karlaftis, M. G. 2004. "A DEA Approach for Evaluating the Efficiency and Effectiveness of Urban Transit Systems." European Journal of Operational Research, 152 (2): 354-364.

Kerstens, K. 1996. "Technical Efficiency Measurement and Explanation of French Urban Transit Companies." Transportation Research Part A, 30 (6): 431-452.

Kumar, S. 2011. "State Road Transport Undertakings in India: Technical Efficiency and Its Determinants." Benchmarking: An International Journal, 18 (5): 616-643.

Lao, Y., and L. Liu. 2009. "Performance Evaluation of Bus Lines with Data Envelopment Analysis and Geographic Information Systems." Computers, Environment and Urban Systems, 33: 247- 255.

Levaggi, R. 1994. "Parametric and Non Parametric Approach to Efficiency: The Case of Urban Transport in Italy." Studi Economici, 49: 67-88.

Li, J ., X. Chen, X. Li, and X. Guo. 2013. "Evaluation of Public Transportation Operation Based on Data Envelopment Analysis." Social and Behavioral Sciences, 96: 148-155.

Nissim, D., and S. H. Penman. 2001. "Ratio Analysis and Equity Valuation: From Research to Practice." Review of Accounting Studies, 6: 109-154.

Nolan, J. F. 1996. "Determinants of Productive Efficiency in Urban Transit." Logistics and Transportation Review, 32 (3): 319-342.

Nolan, J. F., P. C. Ritchie, and J. E. Rowcroft. 2002. "Identifying and Measuring Public Policy Goals: ISTEA and the US Bus Transit Industry." Journal of Economic Behavior \& Organization, 48: 291-304.

Odeck, J. 2000. "Assessing the Relative Efficiency and Productivity Growth of Vehicle Inspection Services: An Application of DEA and Malmquist Indices." European Journal of Operational Research, 126 (3): 501-514.

Odeck, J.(2006. "Congestion, Ownership, Region of Operation, and Scale: Their Impact on Bus Operator Performance in Norway." Socio Economic Planning Sciences, 40 (1): 52-69.

Perelman, S., and D. Santin. 2009. "How to Generate Regularly Behaved Production Data? A Monte Carlo Experimentation on DEA Scale Efficiency Measurement." European Journal of Operational Research, 199: 303-310.

Pina, V., and L. Torres. 2001. Analysis of the Efficiency of Local Government Services Delivery: An Application to Urban Public Transport." Transportation Research Part A: Policy and Practice, 35 (10): 929-944.

Ramanathan, R. 1999. "Using Data Envelopment Analysis for Assessing the Productivity of the State Transport Undertakings." Indian Journal of Transport Management, 23 (5): 301-312.

Silverman, B. W. 1986. "Density Estimation For Statistics and Data Analysis."

Simar, L. 2007. "How to Improve the Performances of DEA/FDH Estimators in the Presence of Noise? Journal of Production Anul, 28: 183-201. 
Simar, L., and P. W. Wilson. 1998. "Sensitivity Analysis of Efficiency Scores: How to Bootstrap in Nonparametric Frontier Models." Management Science, 4 (1): 49-61.

Staat, M. 2001. "The effect of Sample Size on the Mean Efficiency in DEA: Comment." Journal of Productivity Analysis, 15: 129-137.

United Nations (UN). 2012. World Urbanization Prospects, 2011 Revision (CD-ROM edition). United Nations, Department of Economic and Social Affairs, Population Division.

Viton, P. A. 1998. “Changes in Multi-Mode Bus Transit Efficiency, 1988-1992." Transportation, 25 (1): 1-21.

Waters, W. G., and M. W. Tretheway. 1998. "Comparing the Total Factor Productivity and Price Performance: Concepts and Applications to Canadian Railways." Journal of Transport Economics and Policy, 33: 209-220.

Yu, M.-M., and C.-K. Fan. 2009. "Measuring the Performance of Multimode Bus Transit: A Mixed Structure Network DEA Model." Transportation Research Part E, 45: 501-515.

Yu, M.-M. 2008. "Assessing the Technical Efficiency, Service Effectiveness, and Technical Effectiveness of the World's Railways through NDEA Analysis." Transportation Research Part A, 42 (6): 1283-1294.

\section{About the Authors}

DeVaraj Hanumappa (devaraj@cistup.iisc.ernet.in) is currently a Ph.D student in the Department of Civil Engineering at Indian Institute of Science (IISC), Bangalore. He is working in the area of socioeconomic impact evaluation of large development programs.

Dr. Parthasarathy Ramachandran (parthar@mgmt.iisc.ernet.in) is an Associate Professor in the Department of Management Studies at IISC. His teaching and research interests are in the areas of pricing and revenue management.

DR. T. G. SithaRAm (sitharam@civil.iisc.ernet.in) is a Professor in the Department of Civil Engineering at IISc. His research and teaching interests are in the area of geotechnical engineering. He was the founding chairman of Center for infrastructure, Sustainable Transportation and Urban Planning (CiSTUP) at IISc, which seeks to address issues related to transportation and Infrastructure in an urban environment.

S. LAKSHMANA (lakshman_1975@yahoo.co.in) is currently a divisional mechanical engineer at Karnataka State Road Transport Corporation. He holds a Master of Engineering degree from the Department of Civil Engineering, IISc. 